\title{
Uma proposta de formação em contexto para as professoras de uma creche municipal de Fortaleza ${ }^{1}$
}

\section{A continuing education program in context for teachers in a municipal daycare in Fortaleza}

\author{
Antonia Emanuela Oliveira de Lima² \\ Fátima Sampaio Silva ${ }^{3}$
}

\begin{abstract}
RESUMO
Esta pesquisa analisou a contribuição de uma formação em contexto para melhorar a qualidade das práticas pedagógicas das professoras de uma creche municipal em Fortaleza. Fundamentou-se nas perspectivas de Nóvoa (1997) e Shön (1997), caracterizando-se como uma pesquisa qualitativa, uma pesquisa-ação colaborativa, desenvolvida na instituição onde as professoras trabalhavam. O processo de formação em contexto foi planejado e implementado a partir da indicação pelas professoras dos temas que seriam o alvo dos estudos e da intervenção na creche. Baseando-se nestes temas, foram elaborados planos de estudos, contendo os objetivos de cada encontro de formação, a metodologia de trabalho e apontando as leituras que seriam objeto de reflexões e discussões nestes encontros. Utilizou-se também um recurso classificado por Ibiapina (2008) como videoformação, que possibilitou a análise pelas professoras de suas próprias práticas. Os dados analisados qualitativamente indicaram que, no decorrer dos dez encontros,
\end{abstract}

DOI: $10.1590 / 0104-4060.36986$

1 Pesquisa financiada pela Coordenação de Aperfeiçoamento de Pessoal de Nível Superior (CAPES) - Programa de Orientação e Operacionalização da Pós-Graduação Articulada à Graduação (PROPAG).

2 Universidade Federal do Ceará, Economia Doméstica. Fortaleza, Ceará, Brasil. Setor de Desenvolvimento Humano. Av. Mister Hull, 2977. Campus do Pici, Bloco 860, Bairro Pici. CEP: 60356-001.

3 Universidade Federal do Ceará, Programa de Pós-Graduação em Educação Brasileira Linha Desenvolvimento, Linguagem e Educação da Criança. Fortaleza, Ceará, Brasil. Rua Waldery Uchoa, 1, Campus do Benfica, Bairro Benfica. CEP: 60020-110. 
as professoras analisaram suas práticas à luz dos conhecimentos que estavam sendo construídos e simultaneamente introduziram modificações nas mesmas, visando à melhoria da qualidade. Ao final da formação, por meio de depoimentos orais e escritos, as professoras revelaram um alto grau de satisfação com a formação da qual ativamente participaram. Após a formação, observações feitas pelas pesquisadoras nas salas da creche evidenciaram mudanças nas suas rotinas. É possível, pois, constatar a eficácia do trabalho colaborativo envolvendo pesquisadores e professores para a melhoria das práticas pedagógicas em creches.

Palavras-chave: formação de professores; creche; trabalho colaborativo.

\begin{abstract}
This study examined the contribution of a continuing education program on the quality of its teachers' pedagogic practices, with the aim of improving them, in a municipal daycare in Fortaleza. It was based on Novoa (1997) and Shön (1997) and it may be characterized as a qualitative collaborative action research, developed in the daycare where those teachers worked. The continuing education program was planned and developed considering the subjects indicated by the teachers as the themes which would be the target of studies and intervention in that daycare. Considering these themes, study plans were drawn up, containing the objectives of each meeting and the methodology. The plan indicated the books and articles that should be read and discussed in the meetings. A technique called "videoformation" by Ibiapina (2008) was used, which made possible that teachers analyzed their own practices. The results taken from a qualitative data investigation indicated that, during the ten meetings, the teachers assessed their practices, considering the knowledge that was being built and they simultaneously introduced changes in their practices in order to improve their quality. After the formation was over, by means of oral and written statements, the teachers revealed a high degree of satisfaction with the formation in which they actively participated. The researchers observed changes in the teachers' practices after finishing the continuing education program. Since they identified changes in the daycare routines, it is possible to infer that a collaborative work between researchers and teachers may be effective for improving the quality of pedagogic practices in daycares.
\end{abstract}

Keywords: teacher's continuing education; daycare; collaborative work. 


\title{
Introdução
}

Analisando a formação do professor ${ }^{4}$ de Educação Infantil no Brasil, constata-se que esta acompanhou as transformações ocorridas no cenário socioeconômico e político do país, bem como as concepções que nortearam a organização das instituições de Educação. As discussões em torno do tema se intensificaram a partir da década de oitenta, quando a Constituição de 1988 afirmou o direito das crianças à Educação Infantil em creches e pré-escolas, e na década de 90, quando a Lei de Diretrizes e Bases (LDB) de 1996 considerou a Educação Infantil como a primeira etapa da Educação Básica. De acordo com o Art. 62 da Lei 9.394/96: Lei de Diretrizes e Bases (LDB) da Educação Nacional,

\begin{abstract}
A formação de docentes para atuar na educação básica far-se-á em nível superior, em curso de licenciatura, de graduação plena, em universidades e institutos superiores de educação, admitida, como formação mínima para o exercício do magistério na Educação Infantil e nas quatro primeiras séries do ensino fundamental, a oferecida em nível médio, na modalidade Normal (BRASIL, 2001).
\end{abstract}

Desta forma, após a LDB, a função docente antes exercida por um profissional com qualquer nível de escolaridade oficialmente passou a ser responsabilidade de um professor com formação de nível superior ou médio. Contudo, apesar do caráter mandatório da lei, os dados sobre a formação de professores que atuam em creches e pré-escolas brasileiras evidenciam que em muitas instituições públicas e privadas a qualificação dos professores ainda não atende aos critérios da formação mínima exigida.

Apesar dos avanços legais historicamente conquistados com relação à formação inicial e continuada de professores, ainda há inúmeros desafios que necessitam ser enfrentados, para oferecer às crianças uma Educação Infantil de qualidade. Um deles diz respeito à articulação das formações continuadas com as dificuldades e necessidades vivenciadas pelos professores no momento de realizar as diversas ações nas creches e pré-escolas.

4 Os termos professor/professores são utilizados quando nos referimos aos docentes de um modo geral. Os termos professora/professoras são utilizados quando nos referimos às professoras da creche onde a pesquisa foi realizada, pois todas eram do sexo feminino. 
Embora muitos fatores de caráter econômico, político e administrativo tenham relações com o baixo padrão de qualidade das instituições de Educação Infantil, levantamos a hipótese de que os modelos de formação continuada, geralmente caracterizados como "modelo escolar" (FERREIRA, 2000), não estão contribuindo para a transformação das práticas dos professores. Neste trabalho, optamos por romper com o modelo escolar de formação e desenvolver um processo de formação fundamentado no contexto e na experiência dos participantes.

O presente artigo é um recorte de uma tese de doutorado em Educação Brasileira, cujo objetivo foi analisar a contribuição de uma formação em contexto para melhorar as práticas pedagógicas das professoras de uma creche municipal de Fortaleza.

Como arcabouço teórico da pesquisa, recorremos às perspectivas de Nóvoa (1997) e Shön (1997). Para Nóvoa, o desafio atual com relação à formação dos professores é reconhecer que existem algumas deficiências no âmbito científico e conceitual nos programas de formação, uma vez que estes têm ignorado o desenvolvimento pessoal, desconsiderando "que a lógica da atividade educativa nem sempre coincide com as dinâmicas próprias da formação" (NÓVOA, 1997, p. 24). Além disto, muitas formações não valorizam uma articulação entre a formação e os projetos das escolas. Estas premissas dificultam uma formação que considera o desenvolvimento profissional do professor em duas perspectivas: individual e coletiva. Ele argumenta:

A formação deve estimular uma perspectiva crítico-reflexiva, que forneça aos professores os meios de um pensamento autônomo e que facilite as dinâmicas de autoformação participada. Estar em formação implica um investimento pessoal, um trabalho livre e criativo sobre os percursos e os projetos próprios, com vista à construção de uma identidade, que é também uma identidade profissional (NÓVOA, 1997, p. 25).

Ele considera que o professor é parte importante da pessoa e, por isso, o lado profissional deve interagir com o pessoal em todo processo de formação inicial ou continuada. Esse mesmo autor considera importante que a formação seja um processo interativo e dinâmico, pois permite a construção do que ele chamou de "redes de (auto) formação participada". Essas redes admitem que

5 O modelo escolar, segundo Ferreira (2000, p. 62), pressupõe que a formação se assenta numa relação entre formadores e formandos do tipo da relação entre professores e alunos, num espaço do tipo da sala de aula e num programa concebido à margem dos projetos e das situações de trabalho dos professores e das escolas. 
para consolidar espaços de formação mútuos são necessárias a troca de experiências e a partilha de saberes, e, portanto, é indispensável que os professores tenham a oportunidade de dialogar entre si para solidificar conhecimentos da prática profissional. "O desenvolvimento de uma nova cultura profissional de professores passa pela produção de saberes e de valores que deem corpo a um exercício autônomo da profissão docente". (NÓVOA, 1997, p. 26).

Para compreender a importância da reflexividade em um processo de formação em contexto, recorremos aos estudos de Shön (1997) que, discutindo a perspectiva de ensino como prática reflexiva, propôs os conceitos: reflexão na ação, reflexão sobre a ação e sobre a reflexão-na-ação. Ele afirma que um professor reflexivo é capaz de refletir na ação e refletir sobre a reflexão na ação, como exemplificado no seguinte texto:

Um professor reflexivo permite-se ser surpreendido pelo que o aluno faz. Num segundo momento, reflete sobre esse fato, ou seja, pensa sobre aquilo que o aluno disse ou fez e, simultaneamente, procura compreender a razão por que foi surpreendido. Depois, num terceiro momento, reformula o problema suscitado pela situação; talvez o aluno não seja de aprendizagem lenta, mas, pelo contrário, seja exímio no cumprimento das instruções. Num quarto momento, efetua uma experiência para testar a sua nova hipótese; por exemplo, coloca uma nova questão ou estabelece uma nova tarefa para testar a hipótese que formulou sobre o modo de pensar do aluno. Esse processo de reflexão-na-ação não exige palavras (SCHÖN, 1997, p. 83).

Ele conclui que uma prática efetivamente reflexiva deve levar em consideração três dimensões: a primeira delas é entender a compreensão das matérias pelo aluno, isto é, tentar descobrir como ele interpretou ou compreendeu isto ou aquilo; a segunda diz respeito ao tipo de interação que se estabelece entre o professor e o aluno, ou seja, como o professor compreende e responde a seu alunado, e a terceira dimensão é referente ao trabalho que o professor realiza para garantir uma prática reflexiva em meio à burocracia da escola.

Outro autor que se debruçou sobre o tema da formação em contexto foi Ferreira (2000). De acordo com esta autora, na formação em contexto há a articulação entre as situações de trabalho e as práticas formativas. Ela explica:

Numa perspectiva de formação em contexto, ao contrário da formação inspirada pelo modelo escolar, as práticas formativas articulam-se com 
as situações de trabalho e os cotidianos profissionais, organizacionais e comunitários das escolas. A criação de ambientes formativos com caráter permanente é o seu horizonte, tendo em vista o desenvolvimento humano de todos quantos neles participam. Nesse sentido, uma perspectiva de formação em contexto reclama de todos um papel ativo de construtores de saber e não de meros consumidores passivos de programas de formação e "créditos" correspondentes. Assim os professores são considerados sujeitos e não objetos da formação. E, finalmente, se considerarmos que os processos de formação de professores têm implicações na vida das crianças, eles contêm uma dimensão ética que os profissionais que neles participam não podem declinar (FERREIRA, 2000, p. 75).

Desta forma, a formação em contexto não dissocia a formação e a ação, pois considera as situações de trabalho dos professores, os contextos de vida e as aprendizagens das crianças, e, portanto, esse processo formativo "tem em vista o desenvolvimento humano dos profissionais, das crianças, das famílias e das comunidades" (FERREIRA, 2000, p. 62).

Esta pesquisa estabeleceu como objetivo a análise da contribuição de um programa de formação continuada em contexto para a melhoria das práticas pedagógicas de uma creche municipal, em Fortaleza.

\section{Percurso metodológico}

A pesquisa se caracterizou como qualitativa, pesquisa-ação do tipo colaborativa, pois visava, por meio de uma formação em contexto de professores, à construção de conhecimentos e à transformação de uma situação inicial em uma situação desejada. Além disso, a pesquisa colaborativa propicia condições para que os professores reflitam sobre suas ações no ambiente escolar e compreendam sua prática, a partir de uma perspectiva de aperfeiçoamento contínuo. Em síntese, Ibiapina considera a pesquisa colaborativa uma atividade de coprodução de saberes, formação, reflexão e desenvolvimento profissional, "realizada interativamente por pesquisadores e professores com o objetivo de transformar determinada realidade educativa" (IBIAPINA, 2008, p. 31).

Os critérios estabelecidos para a seleção do "lócus" da pesquisa foram os seguintes: a creche municipal deveria ser pública e ter turmas de Infantil II e Infantil III, professores com graduação em Pedagogia e pelo menos dois anos de experiência na Educação Infantil. Dentre aquelas que preencheram esses 
critérios, selecionamos a creche "Brincar é Viver", pois nesta instituição a coordenadora demonstrou grande interesse na pesquisa e concordou em disponibilizar tempo para a formação em contexto. Constituíram, pois, os sujeitos da pesquisa quatro professoras (duas do Infantil II e duas do Infantil III) e a coordenadora da creche.

A creche "Brincar é Viver" é uma instituição anexa de uma escola municipal de Educação Infantil em Fortaleza, mantida pela Secretaria Municipal de Educação desse município, que atende aproximadamente 80 crianças entre dois e três anos de idade em tempo integral.

$\mathrm{Na}$ fase inicial da pesquisa, as professoras e a coordenadora apontaram que os temas planejamento e a avaliação seriam os aspectos da prática pedagógica que deveriam constituir os alvos da pesquisa e da intervenção. A partir dos temas escolhidos, foram elaborados planos de estudos dirigidos compostos de leituras, reflexões e discussões relacionadas com os mesmos.

Os encontros de formação ocorreram no ano de 2012 e fizeram parte do grupo as quatro professoras e a coordenadora pedagógica da creche. Vale ressaltar que, a cada encontro, a equipe recebia impresso um plano de aula contendo o tema, os objetivos, a metodologia que seria utilizada e os recursos necessários para aquele dia. A formação passou a ser orientada por esse plano, que era flexível e proposto colaborativamente pelo grupo. Partindo de uma perspectiva que associa a formação a momentos de reflexão sobre a prática, os encontros foram combinados com a equipe, que se disponibilizou inicialmente a participar de 40 horas de aulas.

Foi utilizado também um recurso classificado por Ibiapina (2008) como videoformação. Trata-se de uma filmagem realizada em dados momentos da prática dos professores com o objetivo de projetá-la para eles, colocando-os assim frente à imagem do seu fazer pedagógico para refletir sobre o que estão assistindo.

Após a projeção do vídeo, as professoras que participaram da pesquisa foram convidadas a descrever, informar e confrontar as imagens observadas com os estudos realizados durante o processo de formação, fazendo, pois, uma reflexão sobre aspectos relacionados com uma prática de qualidade. O percurso metodológico ainda incluiu duas sessões de observação, realizadas quatro semanas após o término dos encontros de formação para verificar se as professoras e a coordenadora estavam pondo em prática os conhecimentos construídos nesses encontros.

Os dados referentes aos encontros foram transcritos, organizados e submetidos a uma análise qualitativa que procurou compreender o processo da

6 Nome fictício para preservar o anonimato da instituição. 
formação continuada em contexto, destacando os significados atribuídos ao mesmo pelos sujeitos.

\section{Resultados e discussões}

Como um dos temas sugeridos pelas professoras foi planejamento, a equipe decidiu que o mesmo seria discutido à luz das novas Diretrizes Curriculares Nacionais para a Educação Infantil (DCNEIs), pois esse documento já estava sendo discutido nas formações ministradas pela Prefeitura Municipal de Fortaleza. Essas diretrizes devem nortear toda a prática docente, pois além de incluírem os temas imprescindíveis para a qualidade na Educação Infantil, contemplam reflexões sobre a concepção de criança, currículo e sobre a importância da Proposta Pedagógica. Além disto, as DCNEIs apresentam como eixos norteadores das práticas educativas as interações e as brincadeiras.

No primeiro e no segundo encontro, discutimos o planejamento das experiências descritas no artigo $9^{\circ}$ do referido documento.

Para iniciar a reflexão sobre o tema, as professoras foram incentivadas a comentar a seguinte afirmativa:

As instituições de Educação Infantil devem assegurar a educação em sua integralidade, entendendo que as DCNEIs reúnem princípios, fundamentos e procedimentos definidos pela Câmara de Educação Básica do Conselho Nacional de Educação, para orientar as políticas públicas na área e a elaboração, planejamento, execução e avaliação de propostas pedagógicas e curriculares de qualidade (BRASIL, 2009).

Pelos comentários que foram tecidos, a equipe demonstrou compreender o que são as Diretrizes, destacando-se entre esses a fala da coordenadora Sofia ${ }^{7}$ : “as Diretrizes são direcionamentos, encaminhamentos, propostas, norte que você tem que se atentar em sala, são direções que você pode tomar para essa faixa etária da Educação Infantil". O grupo todo concordou que esse documento é importante, pois pode direcionar a prática pedagógica de forma que seja respeitado o direito da criança a um atendimento de qualidade.

$7 \mathrm{O}$ nome das pessoas que aparecem neste trabalho é fictício no intuito de preservar a privacidade das mesmas. 
Depois dessas discussões, iniciamos o planejamento das experiências da seguinte forma: cada professora descrevia sua rotina atual e em seguida comentava se as experiências contidas no artigo $9^{\circ}$ das DCNEIs estavam sendo contempladas em seus planejamentos e incluídas na rotina da creche. Após muitas reflexões sobre as leituras feitas e a análise da prática, as professoras compreenderam que o planejamento não pode se resumir a uma listagem de atividades e sua distribuição nos tempos, mas precisa incluir: as experiências a serem desenvolvidas, o porquê das mesmas, o que as crianças aprenderão e como as experiências serão realizadas e avaliadas.

Dando prosseguimento, no terceiro encontro examinamos o tema "O planejamento que contempla o conteúdo do inciso VIII do artigo $9^{\circ}$ : experiências que incentivem a curiosidade, a exploração, o encantamento, o questionamento, a indagação e o conhecimento das crianças em relação ao mundo físico e social, ao tempo e à natureza". Como recursos foram utilizados: as DCNEIs; um texto do Manual de orientações técnico-pedagógicas do Governo do Estado do Ceará; um vídeo chamado "Os quatro elementos" e algumas figuras de Tonucci ${ }^{8}$.

Esse foi um dos encontros no qual a equipe estabeleceu pouca relação com a prática, pois, segundo elas, essas experiências não constavam na rotina da creche de forma sistemática. Ao serem questionadas sobre como estas estavam sendo desenvolvidas na creche "Brincar é Viver", elas silenciaram; apenas a professora Lana comentou "nunca estudei muito sobre esse assunto".

Com a continuidade da discussão, aos poucos elas lembravam e comentavam sobre algumas atividades que envolviam o tema em estudo. Relataram, por exemplo, uma experiência na qual cada criança tinha que cuidar de um "pintinho". Algumas relataram a decepção que tiveram ao descobrir que algumas crianças haviam matado o pinto em casa e desde então não desenvolveram mais nenhuma experiência que envolvesse animais vivos.

Após a leitura e reflexões sobre os materiais mencionados, as professoras compreenderam que as crianças estão inseridas em um mundo físico e social sobre o qual têm uma curiosidade aguçada. Constataram também que não são necessários grandes investimentos por parte da escola para o desenvolvimento de experiências que propiciam às crianças oportunidades de observar, levantar hipóteses, investigar e tirar conclusões sobre os fenômenos naturais e sociais.

No quarto e quinto encontros, exploramos o tema: "O planejamento que contempla o conteúdo do inciso IV do artigo $9^{\circ}$ - experiências que recriem em contextos significativos para as crianças relações quantitativas, medidas, formas e orientações espaçotemporais". Utilizamos como recursos, além das DCNEIs,

8 Francesco Tonucci é um educador italiano, desenhista e ilustrador. Seus desenhos retratam problemas da Educação, principalmente da Educação Infantil. 
o texto intitulado "As crianças e o conhecimento matemático: experiências de exploração e ampliação de conceitos e relações matemáticas", de Priscila Monteiro; os vídeos: "Noções de espaço", "Noções de tempo" e "O brincar e a matemática."

Nesse encontro, as professoras relataram as atividades mais comumente por elas realizadas: contagem das crianças presentes, marcação do calendário e música envolvendo os números. Após a leitura do texto de Monteiro, elas demonstraram uma melhor compreensão de como trabalhar as experiências incluídas neste inciso. Segundo a equipe, o texto esclarece o que significa ensinar e aprender matemática na Educação Infantil, pois o mesmo sugere a organização das atividades em três grandes blocos: espaço e forma, número e sistema de numeração e grandezas e medidas.

Ao discutir o texto e analisar os vídeos, as professoras perceberam que as experiências contidas no inciso IV ainda eram pouco exploradas em suas salas e reconheceram a necessidade de sistematizar melhor o planejamento para incluir atividades que ampliem os conhecimentos matemáticos das crianças. Concluíram ainda que o trabalho com a matemática na Educação Infantil deve partir de práticas sociais vividas pelas crianças nas quais os números, as medidas e as formas estejam presentes. Nádia comentou: "a gente deve começar mostrando para as crianças o número do sapato delas, a idade delas, os números contidos no celular, no canal da televisão, para que elas compreendam que os números fazem parte dos seus cotidianos."

Além disto, o planejamento das experiências precisa ser intencional, sistemático, envolvendo questões que favorecem a busca de soluções para os problemas e o estabelecimento de relações que possibilitem à criança "desenvolver suas capacidades de generalizar, analisar, sintetizar, inferir, formular hipóteses, deduzir, refletir e argumentar" (MONTEIRO, 2010, p. 4).

No sexto e sétimo encontros, estudamos a "Avaliação da prática pedagógica na Educação Infantil”, tema que muito motivou as participantes, pois elas tinham inúmeras dúvidas com relação ao processo avaliativo nessa etapa da educação. Foram utilizados os seguintes recursos: do livro Avaliação mito e desafio: uma perspectiva construtivista, de Jussara Hoffmann (2008), os capítulos "Avaliação como mediação" e "Avaliação na Educação Infantil"; desta mesma autora, o capítulo "Delineando relatórios de avaliação", que faz parte do livro Avaliação na Pré-escola: um olhar sensivel e reflexivo sobre a criança e o vídeo "Avaliação na Educação Infantil - legislação, pesquisa e prática". Incluímos também o capítulo "A avaliação e a observação" do livro: Aprender e ensinar na Educação Infantil, das autoras Bassedas, Huguet e Solé (1999).

Para iniciar a discussão, solicitamos às professoras que relacionassem o termo avaliação a alguma imagem. Algumas delas assim se manifestaram: 
"para mim representa um caderno para fazer as anotações" (NÁDIA); Raissa comentou: "para mim um ponto de interrogação, pois a gente fica se perguntando sobre o que estamos observando"; e Joana completou: "geralmente são as atividades que a gente faz, a gente vai perceber a concentração, a movimentação da criança, o desenvolvimento das crianças".

As concepções reveladas refletem alguns aspectos da perspectiva sobre avaliação, presentes na LDB de 1996, e também propostos pelas DCNEIs. Levantamos a hipótese de que as professoras já têm essa compreensão sobre avaliação porque participaram de cursos de formação continuada nos quais esta perspectiva foi discutida. A fala da professora Nádia: "nós recebemos um livrinho sobre avaliação da prefeitura, que foi nosso primeiro mestre" confirma nossa suposição. No entanto, pelo depoimento da professora Joana, constata-se que o tema avaliação precisava ser explorado pelo grupo:

Eu participei de uma formação que tratou do tema avaliação, mas não adiantou porque era assim: cada professora levava um relatório já pronto e chegava lá, trocava com as outras professoras e cada uma lia o seu. Foi só isso e pronto. A orientadora dizia se estava bom ou se estava mais ou menos, não explicava o motivo. Então não entendi foi nada; eu vi que a orientadora estava totalmente perdida; aí eu fiquei mais perdida ainda. Eu fui mais porque quando eu vi o tema "avaliação na Educação Infantil", eu fiquei logo naquela expectativa, opa! Agora, elas vão dá umas dicas, mas não, pensei que iriam nos fornecer subsídios para realizar os relatórios, mas pelo contrário, fez foi confundir ainda mais (PROFESSORA JOANA).

Constatamos que após as reflexões sobre o material listado e a leitura de relatórios escritos por professores que seguiram todos os passos de uma avaliação mediadora, as professoras conseguiram esclarecer muitas das dúvidas iniciais. Compreenderam, principalmente, que os relatórios na Educação Infantil devem contemplar os seguintes aspectos: o ponto de partida da criança, as experiências vivenciadas por elas; a mediação dos professores, as conquistas e dificuldades da criança.

Discutimos, no oitavo e nono encontros, "O planejamento que contempla o conteúdo do inciso III do artigo $9^{\circ}$ : experiências que possibilitem às crianças experiências de narrativas, de apreciação e interação com a linguagem oral e escrita, e o convívio com diferentes suportes e gêneros textuais orais e escritos".

Os recursos utilizados foram: o vídeo "O conto que as caixas contam" e os seguintes capítulos de livros: "A prática de ler histórias" e "O ambiente 
natural e social e o papel do professor na sala de aula", ambos das autoras Ana Teberosky e Teresa Colomer; o texto "Contribuição da Educação Infantil para a formação do leitor e do escritor", de Suely Amaral Melo, e ainda dois textos da Revista Nova Escola: "Amo segunda feira" e "Roda de conversa".

Nesse encontro, as professoras discutiram sobre as primeiras experiências das crianças com relação à linguagem oral e escrita na Educação Infantil. Inicialmente foram convidadas a relatarem sobre as práticas realizadas durante a rotina que contemplavam a linguagem oral e escrita. Ao descrever as atividades que se relacionavam com as mesmas, tais como: a utilização da ficha do nome das crianças e a leitura de histórias, as professoras revelaram conhecimento limitado sobre como proporcionar experiências que favorecessem o desenvolvimento dessas linguagens.

Prosseguindo nossas discussões sobre o tema em estudo, as professoras descreveram os momentos da roda de história e da roda de conversa, por elas denominada de "rodinha de convivência", na qual realizavam as seguintes atividades: observação do tempo, comemoração dos aniversariantes do dia, estudo do calendário e definição das atividades diárias. Para elas, esse momento é especificamente relacionado com o desenvolvimento da linguagem.

Após algumas considerações sobre as funções da linguagem oral e escrita, foi discutida com o grupo a importância de incluir no planejamento das experiências momentos em que as crianças tivessem oportunidades para comunicar-se por meio da linguagem para ampliar suas capacidades verbais. Para Bassedas, Huguet e Solé (1999) o desenvolvimento da linguagem oral dependerá muito das "experiências linguísticas" nas quais a criança se envolve em casa, na instituição de Educação Infantil e em outros ambientes.

Retornando à discussão sobre a função e a relevância da roda de conversa para o desenvolvimento da linguagem oral, elas constataram que em suas salas esta se destinava principalmente à marcação do calendário, à escolha do ajudante do dia, à comemoração dos aniversários. Não estavam, pois, oferecendo oportunidades para as crianças expressarem oralmente desejos, sentimentos, necessidades, nem para fazerem seus relatos. Compreenderam então que a roda de conversa deve proporcionar a troca de ideias e a interlocução entre os membros do grupo, pois conversando sobre diferentes assuntos, as crianças ampliam seus conhecimentos de si e do mundo.

Concluídas as reflexões sobre os textos e vídeos, foi possível constatar que: as professoras passaram a identificar as outras funções da linguagem além da de comunicação e a compreender a necessidade de incluir no planejamento experiências especificamente voltadas para o desenvolvimento da linguagem oral. Em relação à linguagem escrita, compreenderam que, embora alfabetizar não constitua objetivo da Educação Infantil, as experiências devem possibilitar 
que as crianças nas creches e pré-escolas estabeleçam relações entre a fala e a escrita e ampliem os conhecimentos sobre o código alfabético.

No décimo e último encontro, refletimos sobre a rotina da sala do Infantil II, que foi observada e filmada pelas pesquisadoras. Nesta ocasião, analisamos as cenas do vídeo que mostravam, entre outros aspectos, as diversas atividades distribuídas nos tempos durante um turno completo. Além desse recurso, foi utilizado também o vídeo "Trocando em miúdos" com o objetivo de comparar as cenas desse vídeo com os temas trabalhados durante os encontros.

Esta metodologia possibilitou que as professoras analisassem as suas práticas em tempo real. Embora a filmagem tivesse sido feita na sala do Infantil II, as demais professoras se identificaram com os protagonistas das cenas, pois as situações eram semelhantes em todas as salas. Ibiapina explica a importância das filmagens para o processo de reflexão sobre a prática:

As reflexões retratadas por meio do vídeo auxiliam no exercício de reflexibilidade, formando a consciência reflexiva, dotando esses professores de autonomia que os levam a fazer opções e defendê-las convincentemente. Esse procedimento concilia ação, pesquisa, reflexão e formação, já que emerge como recurso por meio dos quais as observações do contexto da sala de aula se tornam mais objetivas. As situações vivenciadas no ambiente didático da aula são recriadas pela ação do vídeo, tornando-se objeto de reflexão e análise compreensiva do que foi observado. Os professores, libertos dos condicionamentos impostos pela situação prática, externalizam conceitos, conflitos e as teorias subjacentes às práticas pedagógicas (IBIAPINA, 2008, p. 80).

O exercício reflexivo fundamentou-se nos estudos realizados durante os encontros e as perguntas que nortearam a discussão foram: que momento da rotina apresenta o vídeo? Qual o planejamento implícito? Que experiências as crianças estão tendo a oportunidade de experimentar? O que elas estão aprendendo? Essas perguntas transcenderam os temas trabalhados na formação em contexto e, portanto, suscitaram novas necessidades e questionamentos.

Para Ibiapina (2008), por meio das filmagens as professoras têm a oportunidade de relatar oralmente as experiências vividas, tomando consciência de sua ação para poder em seguida transformá-la. Com relação à cena analisada, estabeleceram um diálogo, descrevendo a percepção sobre elas próprias, tentando justificar as falhas apontadas pelo grupo e procurando uma alternativa para melhorar. 


\section{Considerações finais}

Como anunciado anteriormente, na formação em contexto optamos por um modelo denominado interativo-reflexivo, de Demailly (1997). Segundo a autora, a eficácia desse modelo fundamenta-se no fato de que ele é o único que leva em consideração as características e as experiências das professoras e das crianças; aborda a prática de uma maneira global e permite a construção de novos saberes profissionais. Ressaltamos que a equipe pedagógica da creche não apenas foi receptiva, mas demonstrou compromisso e envolvimento nos dez encontros, apesar de os mesmos terem sido realizados após um longo dia de trabalho.

Entre as características da equipe que, possivelmente, determinaram esta postura, destacamos alguns fatores, tais como: todas as professoras têm nível superior, algumas já cursaram pós-graduação; todas são efetivas; trabalham juntas há muito tempo e contam com o apoio da coordenadora. De acordo com Garcia (1997), três tipos de atitudes são necessários para um ensino reflexivo: uma mentalidade aberta, a responsabilidade e o entusiasmo. Como percebemos essas atitudes nas professoras e na coordenadora, concluímos que estas foram essenciais para as reflexões feitas por elas com base em suas práticas.

Os comentários das participantes, fundamentados na reflexão sobre a ação, revelaram a sensibilidade que cada uma apresentava em relação às situações-problema que ocorriam naquele contexto. Enquanto uma professora justificava as inadequações aparentes por falta de infraestrutura, outra já relatava o que havia planejado, visando modificar a situação existente na creche. Como exemplo, citamos o caso dos brinquedos, que antes da formação ficavam guardados em armários e depois passaram a ser disponibilizados em prateleiras baixas.

A técnica de análise das filmagens possibilitou a reflexão coletiva sobre as mudanças ocorridas no contexto da creche, fundamentadas nos temas discutidos durante os encontros, que incluíram o planejamento das diferentes experiências descritas pelas DCNEIs, focalizando especificamente aquelas relacionadas com a matemática, as ciências naturais e sociais, a linguagem oral e escrita e a avaliação. A análise das cenas também permitiu que as professoras percebessem que as questões negativas levantadas constituíam um problema de todas e não apenas da professora Nádia, cuja sala foi filmada.

Após a análise das filmagens, as professoras responderam a um instrumental de avaliação. Seus depoimentos revelaram um grau de satisfação elevado com o modelo de formação do qual participaram, indicando, pois, que o trabalho colaborativo entre pesquisadores e professores pode ser eficaz para promover 
mudanças significativas nas práticas. Para a pergunta: "qual a relevância dos encontros para a sua prática pedagógica?" registramos muitas respostas que dão suporte a essa afirmação. A professora Joana escreveu: "ajudou muito na compreensão de vários temas e a desenvolver melhor as atividades com nossas crianças". A professora Raissa assim se expressou:

Os encontros nos levaram a refletir sobre a nossa prática diária, sobre planejamento e sobre avaliação e registro. Pensando sobre tudo isso ficou fácil observar falhas e pontos a serem melhorados. Também percebemos aspectos positivos da nossa prática. O que não estava tão positivo assim, aos poucos, está sendo modificado. Várias questões refletidas durante os encontros foram levadas efetivamente para a minha prática pedagógica. (PROFESSORA RAISSA)

Nesse cenário, expressamos a convicção de que a formação em contexto contribuiu para que as professoras revisitassem suas práticas e, coletivamente, organizassem ações pedagógicas no intuito de oferecer às crianças experiências significativas e prazerosas que caracterizam uma Educação Infantil de qualidade. Embora não possamos afirmar que o processo de mudança terá plena continuidade, pois está altamente condicionado por fatores de ordem econômica, política e administrativa, ressaltamos que observações feitas na creche, um semestre após a formação, evidenciaram a continuidade de algumas práticas: os brinquedos e livros estavam expostos, as atividades eram mais diversificadas e as professoras pareciam mais atentas às necessidades das crianças.

\section{REFERÊNCIAS}

BASSEDAS, E.; HUGUET, T.; SOLÉ, I., A prática educativa I: organização e planejamento. In: Aprender e ensinar na Educação Infantil. Porto Alegre: Artes Médicas Sul, 1999.

BRASIL. Constituição da República Federativa do Brasil de 1988. Brasília, 05 de outubro de 1988. Disponível em: <http://portal.mec.gov.br>. Acesso em: 15/05/2011.

BRASIL. Lei no. 9.394, de 20 de dezembro de 1996. Estabelece as Diretrizes e Bases da Educação Nacional. Diário Oficial da União, Brasília, DF, 23 dez. 1996. Disponível em: $<$ http://portal.mec.gov.br>. Acesso em: 15/05/2011. 
BRASIL. Lei no ${ }^{\circ}$ 10.172, de 9 de janeiro de 2001. Aprova o Plano Nacional de Educação e dá outras providências. Diário Oficial da União, Brasília, DF, 10 jan. 2001. Disponível em: <http://portal.mec.gov.br>. Acesso em: 15/05/2011.

BRASIL. Ministério da Educação e do Desporto. Resolução n ${ }^{\circ}$, de 17 de dezembro de 2009. Fixa as Diretrizes Curriculares Nacionais para a Educação Infantil. Diário Oficial da União, Brasília, DF, 18 dez. 2009.

DEMAILLY, L. C. Modelos de formação contínua e estratégias de mudança. In: NÓVOA, A. (Org.). Os professores e sua formação. Lisboa: Temas de educação - 1. Dom Quixote Instituto de Inovação Educacional, Nova Enciclopédia 1997. Cap. 7, p. 139-158.

FERREIRA, F. I. A formação e os seus efeitos: do modelo escolar à formação em contexto. In: FORMOSINHO, J. O. (Org.). Associação criança: um contexto de formação em contexto. Braga: Livraria Minho, 2000. Cap. 3, p. 63-79.

GARCIA, C. M. A formação de professores: novas perspectivas baseadas na investigação sobre o pensamento do professor. In: NÓVOA, A. (Org.). Os professores e a sua formação. Lisboa: Temas de educação - 1. Dom Quixote Instituto de Inovação Educacional, Nova Enciclopédia 1997. Cap. 3, p. 51-76.

HOFFMANN, J. Avaliação, mito \& desafio: uma perspectiva construtivista. Porto Alegre: Mediação, 2008.

IBIAPINA, I. M. L. M. Pesquisa colaborativa: investigação, formação e produção de conhecimentos. Brasília: Liber Livro, 2008. (Série Pesquisa).

MONTEIRO, P. As crianças e o conhecimento matemático: experiências de exploração e ampliação de conceitos e relações matemáticas. 2010. Disponível em: <www.mec.gov. br>. Acesso em: 20/05/2012.

NÓVOA, A. Formação de professores e profissão docente. In: NÓVOA, A. (Org.). Os professores e a sua formação. Lisboa: Temas de educação - 1, Dom Quixote Instituto de Inovação Educacional, Nova Enciclopédia 1997. Cap. 1, p. 15-34.

SHÖN, D. A. Formar professores como profissionais reflexivos. In: NÓVOA, A. (Org.). Os professores e a sua formação. Temas de educação - 1. Lisboa: Dom Quixote Instituto de Inovação Educacional, Nova Enciclopédia 1997. Cap. 4, p. 77-92.

Texto recebido em 30 de junho de 2014. Texto aprovado em 13 de dezembro de 2014. 